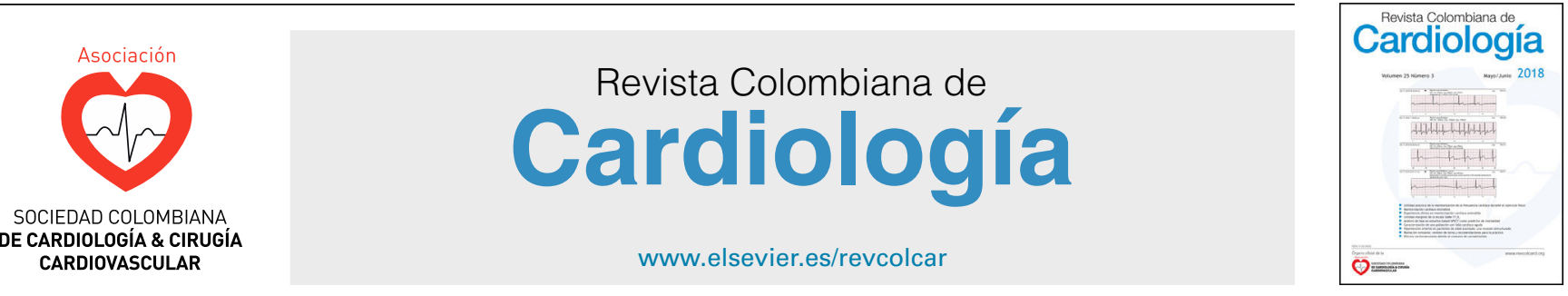

CARDIOLOGÍA DEL ADULTO-ORIGINAL

\title{
Uric acid and salt intake as predictors of incident hypertension in a primary care setting
}

\author{
Daniéster Braga a , Maria Luiza Garcia Rosa ${ }^{a}$, Ronaldo Altenburg Gismondi ${ }^{b}$, \\ Jocemir Ronaldo Lugon ${ }^{b}$, Karla Torres ${ }^{a}$, Bárbara Nalin ${ }^{a}$, Hye Kang ${ }^{a}$, \\ Verônica Alcoforado ${ }^{a}$, Diana María Martínez Cerón ${ }^{a, c, *}$
}

\author{
a Department of Epidemiology and Biostatistic, Universidade Federal Fluminense, Brazil -Hospital Universitário Antônio Pedro, \\ Rua Marques do Parana, Niteroi, Brazil \\ ${ }^{\mathrm{b}}$ Department of Clinical Medicine, Universidade Federal Fluminense, Brazil -Hospital Universitário Antônio Pedro, Rua Marques \\ do Parana, Niteroi, Brazil \\ c Department of Social Medicine and Family Health, Universidad del Cauca, Popayán, Colombia
}

Received 18 April 2018; accepted 22 July 2019

Available online 11 November 2019

\author{
KEYWORDS \\ Hypertension; \\ Incidence; \\ Sodium; \\ Dietary; \\ Uric acid; \\ Blood pressure; \\ Primary health care
}

\begin{abstract}
Background: Hypertension is responsible for a substantial number of deaths due to cardiovascular disease and stroke. A crucial step toward its control is the identification of modifiable predictors of hypertension.

Objectives: To estimate the relationship between salt intake, serum uric acid and incident hypertension in a primary care setting.

Methods: Retrospective cohort of the CAMELIA study in which a non-randomized sample of 1098 participants who were $\geq 20$ year-old was recruited from a primary care program. Originally, the sample consisted of hypertensive, diabetic and non-diabetic/non-hypertensive subjects. For the analysis, 258 participants with blood pressure (BP) lower than $140 / 90 \mathrm{~mm} \mathrm{Hg}$ not using antihypertensive drugs and without diabetes mellitus were included. Five years after the first visit, their medical records were reviewed. Patients were divided into two groups according to $B P$ in the first visit: normal BP group (systolic BP $\leq 120 \mathrm{~mm} \mathrm{Hg}$ and diastolic BP $\leq 80 \mathrm{~mm} \mathrm{Hg}$ ) and high-normal BP group (systolic BP 121-139 mm Hg and/or diastolic BP 81-89 mm Hg).

Results: In multivariate analysis, high-normal BP, hyperuricemia and salt intake $\geq 6 \mathrm{~g} /$ day predicted incident hypertension. In participants of thenormal BP group, high salt intake conferred the highest risk. In the high-normal BP group, smoking and serum uric acid were found to be the most important ones.
\end{abstract}

\footnotetext{
* Corresponding author.

E-mail address: mcdianamaria@gmail.com (D.M. Martínez Cerón).
} 
Conclusion: In a healthy, multiethnic, and normotensive population from an urban primary care program, high-normal BP, hyperuricemia and high salt intake were found to be predictors of incident hypertension.

( 2019 Published by Elsevier España, S.L.U. on behalf of Sociedad Colombiana de Cardiología y Cirugía Cardiovascular. This is an open access article under the CC BY-NC-ND license (http:// creativecommons.org/licenses/by-nc-nd/4.0/).

\section{PALABRAS CLAVE}

Hipertensión; Incidencia;

Sodio;

Dietético;

Ácido úrico;

Presión arterial;

Atención primaria

\section{Introduction}

Cardiovascular diseases are the world leading cause of death $^{1,2}$. Hypertension is responsible for at least $45 \%$ of deaths due to cardiovascular disease and $51 \%$ of deaths due to stroke ${ }^{1,2}$. The most common risk factors for hypertension are age, gender, race, chronic kidney disease, body mass index, unhealthy diet and salt intake, stress, smoking, sedentarism and alcohol ${ }^{1}$. A crucial step toward preventive strategies would be the identification of modifiable predictors of hypertension.

High salt intake is thought to be one of the most important predictors of incident hypertension $(\mathrm{IH})^{3,4}$. The majority of the studies supports a role for high salt intake in the development of hypertension ${ }^{5-7}$ but the subject is still a matter of controversy. Otsuka et al., for instance, did not observe a relationship between salt intake and $\mathrm{IH}^{8}$.

Hyperuricemia often accompanies metabolic syndrome, hypertension and diabetes ${ }^{9,10}$. Previous studies have confirmed an important association between uric acid and hypertension $^{11-13}$ and a recent meta-analysis showed that hyperuricemia may increase the risk of hypertension incidence $^{14}$.

We decided to explore the relationship of both, uric acid and salt intake, with incident hypertension in a relatively young and healthy primary care population.

\section{Methods}

\section{Study population}

Subjects were recruited from a public primary care program in Niteroi, Rio de Janeiro, Brazil. Thirteen primary care settings were selected by convenience, covering all administrative areas of the city. Inclusion criteria were $\geq$ 20 years-old and acceptance of written informed consent. Exclusion criteria were pregnancy, immune deficiencies and use of immunosuppressive drugs. The local ethics committee approved the study (CMM/HUAP-220/05). 


\section{Study design}

This study was a retrospective cohort of the CAMELIA study (Cardiometabolic Renal Family Study). Methodological details of the study protocol are published elsewhere ${ }^{15}$. Briefly, the CAMELIA study involved 1.098 individuals from primary care settings who were enrolled following an initial selection of index cases. To be accepted as an index case, individuals needed to have a partner who agreed to participate in the study and have at least one child between 12 and 30 years-old who would also enroll. Index cases were divided into four groups based on the presence of hypertension and diabetes mellitus. In this study, only the group without hypertension and diabetes mellitus was included for analysis.

In the initial visit, patients were scheduled to clinical evaluation at the primary care setting andfasting blood samples were taken for analysis. Five years later, participantś medical records were reviewed and information about clinical evaluation, blood pressure (BP) and blood assays was gathered from the two most recent visits that occurred after the baseline visit. We analyzed BP readings, antihypertensive medication prescription, smoking history, blood analysis, including serum uric acid and salt intake in the whole population. Furthermore, participants were divided into two groups according to $\mathrm{BP}$ readings at the first visit (normal BP group and high-normal BP group) to better analyze the factors that could influence the emergence of $\mathrm{IH}$.

\section{Clinical evaluation}

Office BP was obtained using an electronic device (model HEM-705CP, Omron Healthcare Inc., Lake Forest, IL, US) and an appropriate sized cuff. Before measurement, patients were seated for 30 minutes and refrained from smoking and caffeine ingestion. Three readings, one minute apart, were done, and the average of these measurements was defined as the patient BP. Body mass index (BMI) was calculated as body weight (in kilograms) divided by squared height (in meters). Waist circumference was measured at the midpoint between the lower rib margin and anterior superior iliac crest and was considered high if $\geq 94 \mathrm{~cm}$ in males and $\geq$ $80 \mathrm{~cm}$ in females. Patients were said to be smokers if they smoked more than 100 cigarettes in their life.

\section{Parameters}

At baseline, hypertension, normal BP and high-normal $\mathrm{BP}$ were defined according to $\mathrm{VI}$ Brazilian Guidelines on Hypertension ${ }^{16}$. Briefly, subjects with $\mathrm{BP}$ more than $120 / 80 \mathrm{~mm} \mathrm{Hg}$ and less than $140 / 90 \mathrm{~mm} \mathrm{Hg}$ were classified as high-normal BP group and those with $B P \leq 120 / 80 \mathrm{~mm} \mathrm{Hg}$ as normal BP group. During follow-up, incident hypertension was defined as $B P \geq 140 / 90 \mathrm{~mm} \mathrm{Hg}$ and/or prescription of antihypertensive medications. High uric acid was defined as serum levels $\geq 6.8 \mathrm{mg} / \mathrm{dl}$ for males and $\geq 5.4 \mathrm{mg} / \mathrm{dl}$ for females. High salt intake was defined as $\geq 6 \mathrm{~g} /$ day. Urinary biochemical parameters were measured in a first morning urine sample and included creatinine $(\mathrm{Cr})$, albumin and sodium. The sodium excretion index ( $\mathrm{mEq} \mathrm{Na} / \mathrm{g}$-creatinine) was estimated by determining the rate of excretion of $\mathrm{Na}$
( $[\mathrm{Na}$ in $\mathrm{mEq} / \mathrm{L}$ in a morning urine sample/urinary creatinine in $\mathrm{mg} / \mathrm{dll}]^{* 100)}{ }^{17}$. The calculated sodium excretion index was then converted to salt intake, in grams of sodium chloride. Fasting venous blood was collected to measure total cholesterol, triglycerides, high-density lipoprotein cholesterol, glucose, creatinine, and uric acid. The low-density lipoprotein cholesterol level was calculated by the Friedewald formula. The glomerular filtration rate was estimated (eGFR) by CKD-EPI formula ${ }^{18}$.

\section{Statistical analysis}

Data are presented as mean \pm standard deviation for continuous variables and absolute and relative frequencies for categorical variables unless otherwise specified. Student $t$ test and chi-square were used to compare, respectively, continuous, and categorical variables. Crude and adjusted relative risks were estimated by single and multiple Poisson regression models. The models were performed using generalized estimating equations (GEE), which are suitable for non-independent observations, since the unit for inclusion in the original study was family. The variables that reached significance of 0.10 in the univariate analysis were included in the multiple models. Values of $p<0.05$ were considered to be significant at the multiple models. In addition, a log rank test was run to determine cumulative incidence of hypertension. Statistical analyses were performed using SPSS v. 21.0 (Statistical Package for Social Sciences, Chicago, USA).

\section{Results}

Of the 1098 CAMELIA's participants, 258met our inclusion criteria. The median time of follow-up was 44 months (7 - 61 months). Baseline characteristics of subjects are in Table 1. There were 161 individuals in normal BP group and 97 in high-normal BP group.

Incident hypertension occurred in 42 (16.3\%) patients and was similar in men and women $(15.0 \%$ vs. $17.1 \%, p=0.731)$. Cumulative incidence rates of hypertension in normal BP and high-normal BP groups are shown in Figure 1. In a crude analysis for the whole sample, $\mathrm{IH}$ was associated with age, smoking, high-normal BP, BMI, waist circumference, HDLcholesterol, uric acid, and salt intake. In the multivariate analysis, smoking, high-normal BP, hyperuricemia, and high salt intake were kept aspredictors of IH (Table 2). When the analysis was performed separating the two groups, high salt intake was found to be the only predictor of $\mathrm{IH}$ in the normal BP group. In contrast, smoking and hyperuricemia were the factors that predict IH in the high-normal BP group (Table 2).

\section{Discussion}

In this retrospective cohort, we evaluated the relationship between uric acid, salt intake and incident hypertension. For this, we studied a sample derived from a population assisted by a primary care program, originallyenrolled in the CAMELIA study, five years after the first visit. For the present study, only healthy and young participants were selected bypassing metabolic syndrome and/or chronic kidney disease as confounders that could distort the relationship 
Table 1 Baseline characteristics of the study participants.

\begin{tabular}{|c|c|c|c|c|}
\hline & All $(n=258)$ & Normal BP $(n=161)$ & High-normal BP $(n=97)$ & $p$ value \\
\hline Age (years) & $36.9 \pm 11.1$ & $34.2 \pm 11.2$ & $41.5 \pm 11.4$ & $<0.001$ \\
\hline Male, n (\%) & $100(38.8)$ & $45(28.0)$ & $55(56.7)$ & $<0.001$ \\
\hline Black, n (\%) & $95(37.4)$ & $65(36.3)$ & $30(40.0)$ & 0.680 \\
\hline BMI $\left(\mathrm{kg} / \mathrm{m}^{2}\right)$ & $25.5 \pm 4.4$ & $24.8 \pm 4.0$ & $26.6 \pm 4.7$ & 0.002 \\
\hline Waist circumference $(\mathrm{cm})$ & $81.3 \pm 10.2$ & $78.7 \pm 9.2$ & $85.7 \pm 10.2$ & 0.339 \\
\hline Systolic BP (mm Hg) & $115.2 \pm 11.7$ & $107.8 \pm 7.5$ & $127.4 \pm 5.9$ & $<0.001$ \\
\hline Diastolic BP (mm Hg) & $72.0 \pm 8.2$ & $68.1 \pm 6.2$ & $78.7 \pm 6.9$ & $<0.001$ \\
\hline eGFR $\left(\mathrm{mL} / \mathrm{min} / 1.73 \mathrm{~m}^{2}\right)$ & $99.7 \pm 18.6$ & $101.7 \pm 18.1$ & $96.5 \pm 19.1$ & 0.031 \\
\hline Salt intake estimate (g/day) & $7.4 \pm 4.8$ & $7.2 \pm 4.6$ & $7.7 \pm 5.1$ & 0.391 \\
\hline Uric acid $(\mathrm{mg} / \mathrm{dl})$ & $4.1 \pm 1.3$ & $3.8 \pm 1.2$ & $4.6 \pm 1.4$ & $<0.001$ \\
\hline Glucose (mg/dl) & $93.9 \pm 10.5$ & $51.8 \pm 5.8$ & $52.6 \pm 5.9$ & 0.293 \\
\hline LDL cholesterol (mg/dl) & $114.7 \pm 35.6$ & $110.6 \pm 33.5$ & $121.7 \pm 38.0$ & 0.017 \\
\hline HDL cholesterol (mg/dl) & $51.9 \pm 12.9$ & $52.8 \pm 13.7$ & $50.3 \pm 11.4$ & 0.140 \\
\hline Triglycerides (mg/dl) & $89.6 \pm 50.4$ & $79.8 \pm 41.0$ & $105.9 \pm 59.7$ & $<0.001$ \\
\hline Smokers, n (\%) & $106(41.4)$ & $65(40.4)$ & $41(42.3)$ & 0.795 \\
\hline
\end{tabular}

Mean \pm S.D. unless otherwise specified; BMI, body mass index; BP, blood pressure; $\mathrm{Cr}$, creatinine; eGFR, estimated glomerular filtration rate by CKD-EPI equation; HDL, high-density lipoprotein; LDL, low-density lipoprotein.

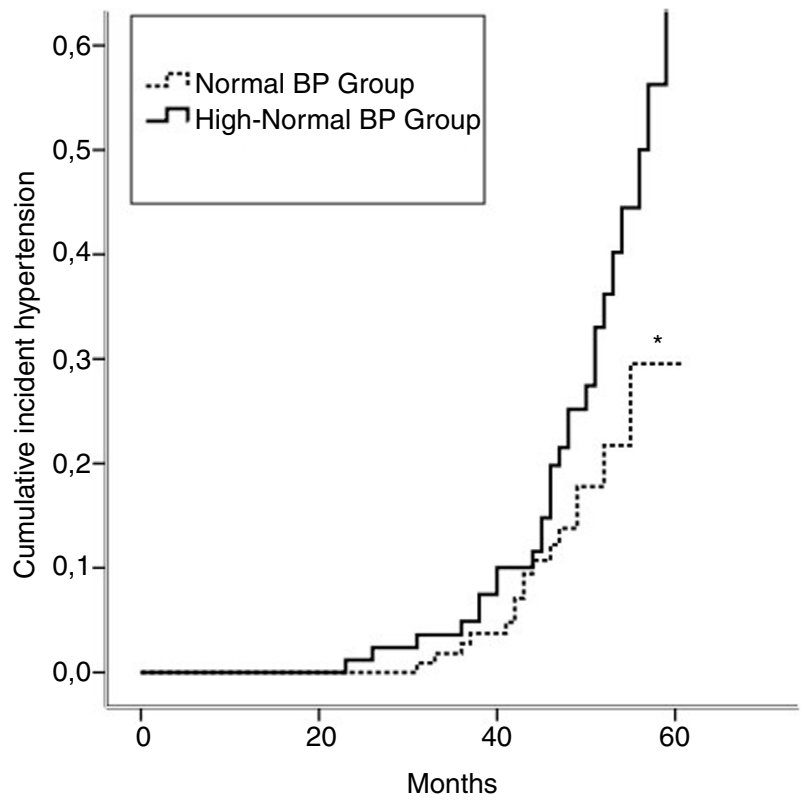

Figure 1 Cumulative incidence rates of hypertension in normal BP and high-normal BP groups. ${ }^{*} \mathrm{p}=0.036$ (log-rank test).

between hypertension, salt intake and uric acid. Consistent with previous studies ${ }^{11,12,14,19,20}$, we showed that smoking, high-normal BP, hyperuricemia, and high salt intake were predictors of $\mathrm{IH}$.

High salt intake may promote hypertension through volume expansion, stimulation of sympathetic nervous system, modifying renin secretion and even promoting inflammation and endothelial dysfunction ${ }^{19}$. Uric acid is associated to hypertension and may promote high blood pressure by reducing pressure dependent natriuresis, activation of the renin-angiotensin-aldosterone system and suppression of nitric oxide ${ }^{9}$. Finally, nicotine activates sympathetic nervous system and elevates blood pressure.
When analyzing the whole population, smoking, hyperuricemia, high salt intake and high-normal BP were found to be predictors of $\mathrm{IH}$. As recently reviewed ${ }^{21}$, the issue of predictors of $\mathrm{IH}$ was the subject of a number of studies, but only a few of them enrolled truly healthy participants. In support to our findings, the Framingham Offspring Studywhose participants were similar to ours regarding age and $\mathrm{BP}$, showed that age, sex (female), BP, BMI, smoking and parental history of hypertension were predictors of $\mathrm{IH}^{22}$. However, they did not evaluate either salt intake or uric acid. In a cohort study involving 118,920 healthy subjects, serum uric acid, age, systolic BP and BMI were also found to be risk factors for $\mathrm{IH}^{12}$. In addition, higher salt intake was associated with increases in uric acid and higher salt intake was an independent risk factor for development of hypertension in individuals with higher uric acidin the PREVEND study ${ }^{19}$.

In the present study, IH predictors were different in patients with normal and high-normal BP. As far as we could know only one study resorted to a similar strategy comparing predictive factors in normal and high-normal BP participants ${ }^{23}$. They did not address the salt intake issue but in some way similar to our results, they reported that age, BP, BMI, serum glucose and uric acid were predictors of $\mathrm{IH}$ in patients with high-normal $\mathrm{BP}^{23}$. On the other hand, only age, BMI and BP were predictors of $\mathrm{IH}$ in normal BP patients. Participants were older and a non-negligible fraction of them was diabetic, factors that can account for the minor differences between studies.

We could not find a definite explanation concerning the differences in the predictive factors of $\mathrm{IH}$ for the normal BP group and the high-normal BP group. If hyperuricemia indeed pave the way for future hypertension in some population groups, our finding of its predictive value in the high-normal BP group could simply be a reflex of an ongoing process.

This study has some limitations. At first, sample size was not very large for this kind of study. Secondly, follow up data was collected from medical records and we could not rule 
Table 2 Adjusted* relative risks of incident hypertension.

\begin{tabular}{|c|c|c|c|}
\hline & \multicolumn{3}{|c|}{$\mathrm{RR}(95 \% \mathrm{Cl})$} \\
\hline & All $(n=258)$ & Normal BP $(n=161)$ & High-normal BP $(n=97)$ \\
\hline \multicolumn{4}{|l|}{ Tobacco } \\
\hline smoker & $2.24(1.16-4.35)$ & $1.24(0.33-4.64)$ & $3.42(1.39-8.41)$ \\
\hline Non-smoker & 1 & 1 & 1 \\
\hline \multicolumn{4}{|l|}{ Blood pressure } \\
\hline High-normal BP & $2.18(1.16-4.09)$ & $\mathrm{N} / \mathrm{A}$ & N/A \\
\hline Normal BP & 1 & $\mathrm{~N} / \mathrm{A}$ & N/A \\
\hline \multicolumn{4}{|l|}{ Waist circumference } \\
\hline High $(M \geq 94 \mathrm{~cm}$ and $F \geq 80 \mathrm{~cm})$ & $1.67(0.96-2.92)$ & $1.44(0.52-4.01)$ & $1.65(0.82-3.30)$ \\
\hline Normal $(\mathrm{M}<94 \mathrm{~cm}$ and $\mathrm{F}<80 \mathrm{~cm})$ & 1 & 1 & 1 \\
\hline \multicolumn{4}{|l|}{ HDL cholesterol } \\
\hline Low $(\mathrm{M}<40 \mathrm{mg} / \mathrm{dl}$ and $\mathrm{F}<50 \mathrm{mg} / \mathrm{dl})$ & $1.38(0.78-2.45)$ & $2.10(0.87-5.06)$ & $0.84(0.39-1.80)$ \\
\hline Normal $(M \geq 40 \mathrm{mg} / \mathrm{dl}$ and $\mathrm{F} \geq 50 \mathrm{mg} / \mathrm{dl})$ & 1 & 1 & 1 \\
\hline \multicolumn{4}{|l|}{ Uric acid } \\
\hline High $(M \geq 6.8 \mathrm{mg} / \mathrm{dl}$ and $\mathrm{F} \geq 5.4 \mathrm{mg} / \mathrm{dl})$ & $2.55(1.27-5.11)$ & $4.95(0.63-38.68)$ & $3.19(1.36-7.47)$ \\
\hline Normal $(\mathrm{M}<6.8 \mathrm{mg} / \mathrm{dl}$ and $\mathrm{F}<5.4 \mathrm{mg} / \mathrm{dl})$ & 1 & 1 & 1 \\
\hline \multicolumn{4}{|l|}{ Salt intake } \\
\hline High & $2.41(1.41-4.10)$ & $4.77(1.84-12.38)$ & $1.31(0.66-2.62)$ \\
\hline Low & 1 & 1 & 1 \\
\hline eGFR $\left(\mathrm{ml} / \mathrm{min} / 1.73 \mathrm{~m}^{2}\right)$ & $0.99(0.98-1.01)$ & $1.00(0.98-1.03)$ & $0.99(0.98-1.01)$ \\
\hline Age (years) & $0.99(0.97-1.03)$ & $0.99(0.94-1.06)$ & $0.99(0.96-1.02)$ \\
\hline
\end{tabular}

*Estimated by Generalized Estimating Equations, Poisson log linear regression. BP, blood pressure; DBP, diastolic blood pressure; eGFR, estimated glomerular filtration rate by CKD-EPI; F, female; HDL, high density lipoprotein; M, male; N/A, not applicable; SBP, systolic blood pressure.

out measurement bias. However, most patients considered hypertensive in follow up visits were under antihypertensive medication, so the probability of misdiagnosis was minimized. Some authors also consider spot urine specimen as a limitation to salt intake estimation. However, 24-hour urinary measurement is not practical for large-scale studies and there are many previous studies validating salt intake estimation from spot urine specimen ${ }^{17,24}$.

\section{Conclusions}

Recognition of modifiable incident hypertension predictors is an important step toward preventive strategies to reduce blood pressure and hence cardiovascular mortality. In the present study, smoking, high-normal BP, hyperuricemia and high salt intake were the most important predictors of $\mathrm{IH}$. Salt intake was the most important predictor in individuals from the normal BP group. On the other hand, smokers and individuals with elevated serum uric acid had the highest risk of $\mathrm{IH}$ in the high-normal BP group. More studies are needed to confirm differences in $\mathrm{IH}$ predictive factors between individuals with normal BP and high-normal BP.

\section{Conflicts of interest}

None.

\section{Acknowledgement of grant support}

None.

\section{References}

1. Huffman MD, Lloyd-Jones DM. Global burden of raised blood pressure. JAMA. 2017;317:142.

2. Campbell NRC, Lackland DT, Lisheng L, Niebylski ML, Nilsson PM, Zhang XH. Using the Global Burden of Disease Study to Assist Development of Nation-Specific Fact Sheets to Promote Prevention and Control of Hypertension and Reduction in Dietary Salt: A Resource From the World Hypertension League. J Clin Hypertens. 2015;17:165-7.

3. Intersalt Cooperative Research Group. Intersalt: an international study of electrolyte excretion and blood pressure. Results for 24 hour urinary sodium and potassium excretion. BMJ. 1988;297(6644):319-28.

4. He FJ, MacGregor GA. A comprehensive review on salt and health and current experience of worldwide salt reduction programmes. J Hum Hypert. 2009;23:363-84.

5. He FJ, Li J, Macgregor GA. Effect of longer term modest salt reduction on blood pressure: Cochrane systematic review and meta-analysis of randomised trials. BMJ. 2013;346:f1325.

6. Aaron KJ, Sanders PW. Role of dietary salt and potassium intake in cardiovascular health and disease: a review of the evidence. Mayo Clin Proc. 2013;88:987-95.

7. Graudal N, Jürgens $G$, Baslund B, Alderman MH. Compared with usual sodium intake, low- and excessive-sodium diets are associated with increased mortality: a meta-analysis. Am J Hypertens. 2014;27:1129-37. 
8. Otsuka T, Kato K, Ibuki C, Kodani E, Kusama Y, Kawada T. Does subjective evaluation of the frequency of salty food intake predict the risk of incident hypertension? A 4-year follow-up study in a middle-aged population. Intern Med J. 2013;43:1316-21.

9. Wu AH, Gladden JD, Ahmed M, Ahmed A, Filippatos G. Relation of serum uric acid to cardiovascular disease. Int J Cardiol. 2015;213:4-7.

10. Kuwabara M. Hyperuricemia, cardiovascular disease, and hypertension. Pulse (Basel, Switzerland). 2016;3(3-4):242-52.

11. Mellen PB, Bleyer AJ, Erlinger TP, Evans GW, Nieto FJ, Wagenknecht LE, et al. Serum uric acid predicts incident hypertension in a biethnic cohort: the atherosclerosis risk in communities study. Hypertension. 2006;48:1037-42.

12. Leiba A, Vinker S, Dinour D, Holtzman EJ, Shani M. Uric acid levels within the normal range predict increased risk of hypertension: a cohort study. J Am Soc Hypertens. 2015;9:600-9.

13. Takase H, Kimura G, Dohi Y. Uric acid levels predict future blood pressure and new onset hypertension in the general Japanese population. J Hum Hypertens. 2014;28:529-34.

14. Wang J, Qin T, Chen J, Li Y, Wang L, Huang $H$, et al. Hyperuricemia and risk of incident hypertension: a systematic review and meta-analysis of observational studies. PLoS One. 2014;9:e114259.

15. Rosa MLG, Falcão PM, Yokoo EM, da Cruz Filho RA, Alcoforado VM, de Souza B, da SN, et al. Brazil's staple food and incident diabetes. Nutrition. 2014;30:365-8.

16. [VI Brazilian Guidelines on Hypertension]. Arq Bras Cardiol. 2010; 95(1 Suppl):1-51.

17. Tanaka T, Okamura T, Miura K, Kadowaki T, Ueshima H, Nakagawa $\mathrm{H}$, et al. A simple method to estimate populational 24-h urinary sodium and potassium excretion using a casual urine specimen. J Hum Hypertens. 2002;16:97-103.

18. Levey AS, Stevens LA, Schmid CH, Zhang YL, Castro AF, Feldman $\mathrm{HI}$, et al. A new equation to estimate glomerular filtration rate. Ann Intern Med. 2009;150:604-12.

19. Forman JP, Scheven L, de Jong PE, Bakker SJL, Curhan GC, Gansevoort RT. Association between sodium intake and change in uric acid, urine albumin excretion, and the risk of developing hypertension. Circulation. 2012;125:3108-16.

20. Otsuka T, Kachi Y, Takada H, Kato K, Kodani E, Ibuki C, et al. Development of a risk prediction model for incident hypertension in a working-age Japanese male population. Hypertens Res. 2015;38:419-25.

21. Echouffo-Tcheugui JB, Batty GD, Kivimäki M, Kengne AP. Risk models to predict hypertension: a systematic review. PLoS One. 2013;8:e67370.

22. Parikh NI, Pencina MJ, Wang TJ, Benjamin EJ, Lanier KJ, Levy $D$, et al. A risk score for predicting near-term incidence of hypertension: the Framingham Heart Study. Ann Intern Med. 2008;148:102-10.

23. Huang J, Sun Y, Niu K, Wan Z, Yao W, Gao Y, et al. Does elevated serum uric acid level predict the hypertension incidence? A Chinese prospective cohort study. Clin Exp Hypertens. 2015;37:498-504.

24. Takase H, Sugiura T, Kimura G, Ohte N, Dohi Y. Dietary Sodium Consumption Predicts Future Blood Pressure and Incident Hypertension in the Japanese Normotensive General Population. J Am Heart Assoc. 2015;4:e001959. 